\title{
Riparian Plants' Morphometry Derived by RGB + Structured-light 3D Scanning within Real Vegetated Flows
}

\author{
Giuseppe Francesco Cesare LAMA ${ }^{凶}$ and Mariano CRIMALDI \\ University of Naples Federico II, Department of Agricultural Sciences, Naples, Italy \\ $\triangle$ giuseppefrancescocesare.lama@unina.it
}

\begin{abstract}
The knowledge of riparian vegetation bio-mechanical and morphometric features is one of the main topics in the analysis of the hydrodynamic interaction between riparian plants and water flow in vegetated streams. In this work, the scanning of real riparian plants was performed through a portable device composed of RGB sensors and structured-light 3D scanner, and the outcomes of the 3D image processing in terms of Plant Area Index (PAI) based on Digital Hemispherical Photography (DHP) were compared and then employed in real-scale hydraulic simulations. The results of this study furnish useful insights to ecohydraulic researchers dealing with ecohydraulic experimental analyses and numerical modeling of real vegetated flows.
\end{abstract}

Keywords: real vegetated flows, 3D scanning, riparian vegetation, morphometry, modeling.

\section{INTRODUCTION}

Predictive and numerical ecohydraulic modeling of vegetated channels aim at investigating the effect of flow - riparian vegetation interaction on their hydrodynamic behaviour, as pointed out by Lama et al. (2020). The Authors reported that one of the main challenges of ecohydraulics is the knowledge of riparian plants' bio-mechanical and morphometric features in the field. in this context, the easiest way to acquire these properties is embodied 3D scanning of riparian reed beds based on structured-light 3D scanner, a portable device which sensors measures the Near-InfraRed (NIR) pattern projected across reed canopy, while an additional InfraRed sensor captures the reflected light pattern. 


\section{PRELIMINARY RESULTS}

The 3D scanning outcomes in terms of Plant Area Index (PAI) of 20 woody riparian vegetation stands were compared to those based on Digital Hemispherical Photography (DHP) processing. The preliminary results of this work will be employed to simulate a vegetated reclamation channel examined by Errico et al. (2019), which performed hydraulic and vegetation measurements at upstream channel's cross-section equipped with an acoustic Doppler velocimeter (ADV), to estimate the accuracy of the hydraulic simulations by comparing the experimental and modeled flow average velocities $U$ and water levels $h$. Figure 1 shows the main processing steps of 3D scans for the examined woody riparian vegetation stands.
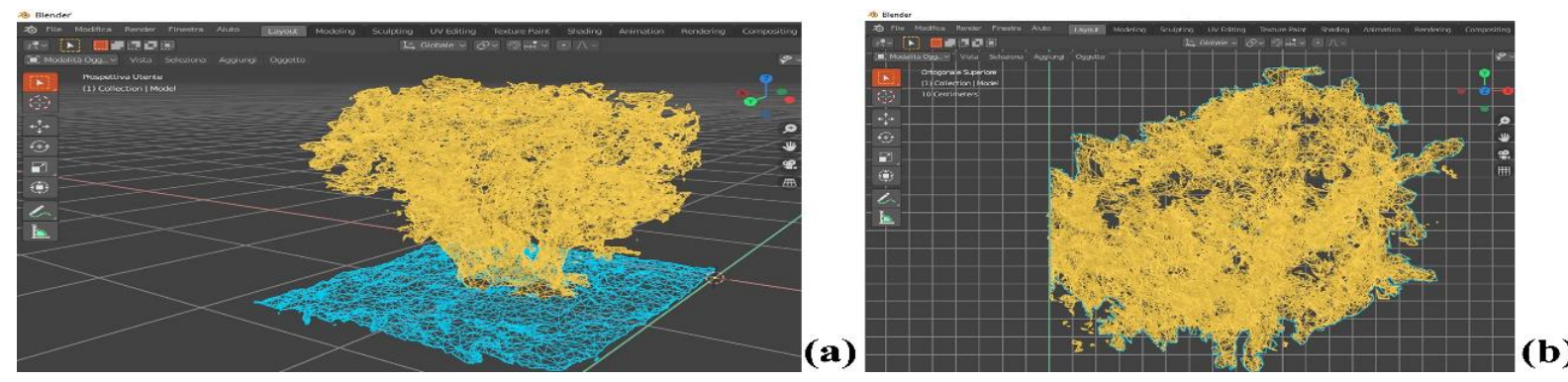

Fig. 1. Examples of 3D scan processing for: (a) soil detection, and (b) PAI estimations.

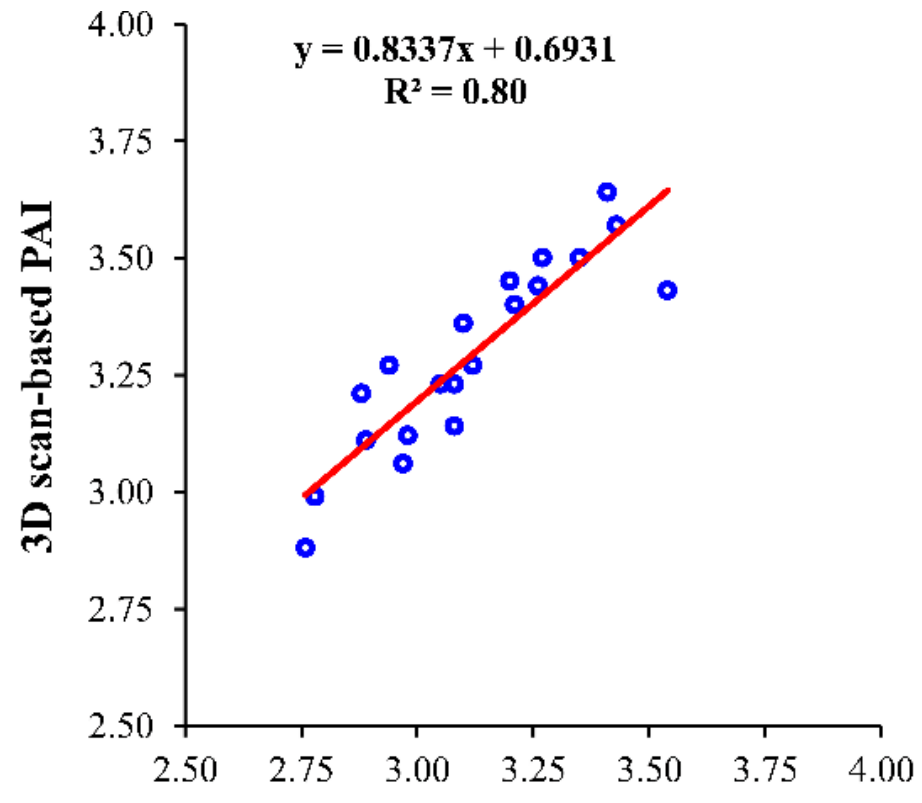

DHP-based PAI
Fig. 2. Comparison of PAI derived by DHP and 3D scanner acquisitions corresponding to 20 woody riparian plants' stands.

In Fig. 2 are shown the accuracy of the hydraulic simulations, performed by comparing the experimental and modeled flow average velocities $U$ and water levels $h$, expressed in $\mathrm{m}$.

Figure 2 shows that DHP- and 3D scan-based PAI estimations of the 20 examined riparian samples are highly correlated, testified by a coefficient of determination $R^{2}=0.80$. 


\section{References}

Lama, G.F.C., A. Errico, S. Francalanci, L. Solari, F. Preti, and G.B. Chirico (2020), Evaluation of flow resistance models based on field experiments in a partly vegetated reclamation channel, Geosciences 10, 2, 47, DOI: 10.3390/geosciences 10020047.

Errico, A., G.F.C. Lama, S. Francalanci, G.B. Chirico, L. Solari, and F. Preti (2019), Flow dynamics and turbulence patterns in a drainage channel colonized by common reed (Phragmites australis) under different scenarios of vegetation management, Ecol. Eng. 133, 39-52, DOI: 10.1016/j.ecoleng.2019.04.016.

Received 22 March 2021

Accepted 12 April 2021 